Mirai. Estudios Japoneses

ISSN-e: 2531-145X

https://dx.doi.org/10.5209/mira.63195

\title{
Las relaciones diplomáticas hispano-japonesas en el marco del conflicto rusojaponés (1904-1905).
}

\author{
Rubén Bartolomé Sopena
}

Recibido: 11 de febrero de 2019 / Aceptado: 15 de abril de 2019

Resumen. La guerra contra Rusia y su resultado marcan un antes y un después en las relaciones diplomáticas y comerciales de Japón con una parte importante de los estados del mundo. El presente trabajo estudia las relaciones diplomáticas entre España y Japón a lo largo del conflicto que mantuvo el segundo con Rusia y en los momentos posteriores al final de la contienda. El objetivo es averiguar si se produjeron cambios en los vínculos entre ambos países a raíz de la guerra rusojaponesa y la victoria nipona y, en caso de producirse variaciones en dicha relación, en qué consistieron.

Palabras clave: Guerra; rusojaponesa; Japón; España; diplomacia.

\section{[en] Spanish-Japanese diplomatic relations in the framework of the Russo- Japanese conflict (1904-1905).}

\begin{abstract}
The war against Russia and its result set a before and an after in the diplomatic and commercial relationship between Japan and a significant part of the world's states. The present work studies the diplomatic relationship between Spain and Japan throughout, and the moments after, the conflict that the latter one maintained with Russia. The objective is finding if there were changes in the ties between both countries as a result of the Russo Japanese war and the Japanese victory; and, in case there were variations in that relationship, analyze those changes.
\end{abstract}

Palabras clave: War; russo-japanese; Japan; Spain: diplomacy.

Sumario. 1. Presentación. 2. Antecedentes. 3. Representación diplomática y funciones durante el conflicto. 4. España ante el estallido del conflicto rusojaponés. 5. La Segunda Flota del Pacífico en Vigo y la reacción nipona. 6. España ante el fin de la guerra rusojaponesa. 7. Conclusiones.

Cómo citar: Bartolomé Sopena, R. (2019). Las relaciones diplomáticas hispano-japonesas en el marco del conflicto rusojaponés (1904-1905), en Mirai. Estudios Japoneses 3(2019), 93-110.

\section{Presentación}

Diplomacia y guerra han sido siempre dos caras de una misma moneda, al punto de considerarse que la segunda es parte de la primera, ya que, de ser necesario, se recu-

\footnotetext{
1 Universidad Autónoma de Barcelona.

E-mail: rubenbartolome5@hotmail.com
} 
rre a la fuerza para hacer valer los argumentos de los agentes implicados. Este sería el caso de la guerra rusojaponesa. Al ver que sus reclamaciones no eran debidamente atendidas en San Petersburgo, los japoneses decidieron sorprender al mundo midiendo sus fuerzas con Rusia.

Lejos de ser un asunto menor o una guerra colonial en un espacio reducido y alejado de los centros de poder de la época, este choque armado fue el principal acontecimiento a nivel internacional de comienzos del siglo XX hasta la Primera Guerra Mundial. Desde su estallido hasta meses posteriores al fin de las hostilidades, las relaciones diplomáticas de ambos contendientes con los demás países fueron evolucionando a medida que se sucedían los combates. Finalmente, la configuración del mundo y las relaciones internacionales, tanto de Japón como de Rusia, experimentaron grandes cambios a raíz de la victoria nipona. ${ }^{2}$

En las últimas décadas, autores como Rotem Kowner o Ian Nish han publicado estudios relacionados con la guerra rusojaponesa. Kowner ha escrito múltiples artículos y libros sobre distintos aspectos del conflicto y su contexto. Nish es autor de The Origins of the Russo-Japanese $\mathrm{War}^{3}{ }^{3}$ un profundo y completo estudio sobre la evolución de las relaciones internacionales en Extremo Oriente y las causas de dicha conflagración.

En lengua española también se han publicado algunos artículos académicos relacionados con dicho conflicto. A modo de ejemplo, podemos citar el artículo Las salpicaduras de una guerra lejana. La guerra ruso-japonesa de 1904-1905 y la neutralidad española según la Prensa española de la época, de Victor Calderón de la Barca ${ }^{4}$ dónde el autor analiza la neutralidad española en el contexto internacional usando la prensa nacional como fuente. Otro ejemplo sería el trabajo La guerra ruso-japonesa a través del Diario de la Rioja, en el cual la autora, Ainhoa Reyes, ${ }^{5}$ analiza el seguimiento que se hizo de la confrontación en el Diario de la Rioja.

El presente trabajo estudia cómo afectó la guerra rusojaponesa a las relaciones diplomáticas entre España y Japón durante dicho conflicto y los instantes posteriores. Por entonces, España era una potencia en declive, ya expulsada de sus posesiones en Oriente y del primer plano internacional, y Japón una potencia en ascenso.

Para ello, se ha consultado principalmente el fondo documental conservado en el Archivo Histórico Nacional (AHN), donde se encuentra parte la documentación referente a las relaciones exteriores de España. Además del Archivo Histórico Nacional, se ha consultado, para algunos asuntos específicos, el Archivo General de la Marina Álvaro de Bazán (AGMAB) y el Archivo General del Cuartel General del Ejército (AGCGE).

\section{Antecedentes ${ }^{6}$}

Para poder estudiar las relaciones hispano-japonesas en el espacio temporal delimitado del presente artículo, primero hay que hacer un breve resumen de los anteceden-

\footnotetext{
Sobre la actitud y el impacto de la guerra rusojaponesa en las principales potencias del momento: Kowner, Rotem (2007).

Nish, Ian (1987).

Calderón de la Barca, Víctor (1995).

Reyes Manzano, Ainhoa (2009).

6 Existen varios estudios sobre las relaciones hispano-japonesas durante el siglo XIX, de estos, los consultados
} 
tes para saber cómo estaban dichos vínculos en el momento que estalla el conflicto rusojaponés.

En el año 1854 Japón firmó el tratado de Kanagawa con Estados Unidos. Quedaba así finalizado su largo periodo de aislamiento autoimpuesto con respecto a buena parte del mundo. Durante los años próximos, se irían sucediendo las firmas de tratados similares con distintos países, principalmente europeos. ${ }^{7}$ A ellos se sumaría España en el año 1868 con la firma del Tratado de amistad, comercio y navegación, enmarcado éste en la política de prestigio que el gobierno español seguía por entonces en Extremo Oriente. ${ }^{8}$

Las posibilidades comerciales y de obtención de mano de obra para las colonias del Pacífico fueron los principales argumentos esgrimidos por los defensores de la firma del tratado entre ambos países. Sin embargo, a efectos prácticos no fue plenamente aprovechado durante la siguiente década, ya que la presencia de intereses españoles en el archipiélago nipón fue escasa. Si bien se estableció una delegación permanente, esta no ejercía una gran actividad propia, se limitaba, en muchos casos, a suscribir las iniciativas de otros países en Japón. A su vez, durante las primeras décadas de reapertura de Japón, éste no se encontraba en situación de practicar una política activa hacia el exterior más allá del envío de estudiantes, embajadas y la compra de maquinaria.

La situación fue evolucionando; Japón llevó a cabo una serie de reformas internas, tales como las reformas económicas y la industrialización, que propiciaron a su vez un cambio en sus políticas internacionales. No perdieron nunca su objetivo principal en esta materia: la derogación de los tratados desiguales. ${ }^{9}$ Dichos tratados situaban a Japón en desventaja frente a las potencias en materias tan importantes como el comercio internacional o la extraterritorialidad. Estos cambios afectaron a las relaciones con España, debido principalmente a la proximidad entre el archipiélago nipón y las posesiones hispanas en el Pacífico. Ante el crecimiento de Japón y las iniciativas que iba tomando en relación con la región, las autoridades hispanas empezaron a desconfiar e incluso a temer a los nipones. ${ }^{10}$ España era incapaz de tomar la iniciativa en las relaciones con Japón, por ello fue este segundo el que encabezaría gran parte de las iniciativas. Esto reflejaba claramente el hecho de que España se encontraba en grandes dificultades mientras que las autoridades japonesas habían logrado iniciar el ascenso de su país en el ámbito internacional.

Los principales temas que vincularon a España y Japón en este periodo fueron el comercio, sobre todo entre los archipiélagos filipino y el nipón; la emigración de mano de obra japonesa a las posesiones hispanas ${ }^{11}$ y la posible compra por parte de Japón de islas pertenecientes al reino de España. ${ }^{12}$ Los dos primeros puntos fueron esgrimidos por múltiples voces hispanas para justificar la necesidad de un pacto con Japón, pero éste fue desaprovechado por España y finalmente fueron los japoneses los que tomaron la iniciativa con la creación de la primera línea directa de vapores

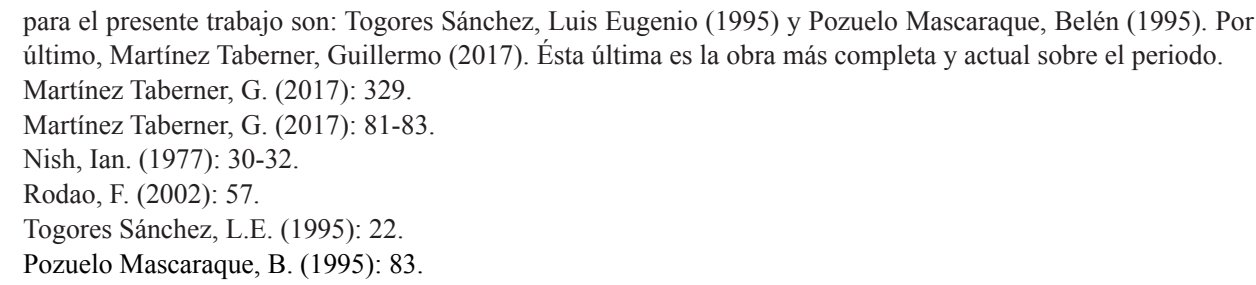


entre Kobe y Manila, ${ }^{13}$ y con el establecimiento de empresas comerciales en posesiones hispanas (en muchos casos sin previa autorización). Con respecto al segundo y tercer punto, jamás se llegó a materializar ningún acuerdo de calado. Enseguida que empezó a surgir la desconfianza, las autoridades españolas vieron la llegada de población japonesa como un peligro. Tampoco había intención alguna de renunciar a ninguna de las posesiones, por pequeña que fuese, por lo que toda propuesta japonesa de compra de islas fue desestimada.

Tal era la desconfianza ante el creciente Japón, que incluso la reapertura del consulado nipón de Manila en 1896 fue visto como una actividad sospechosa. Así se pronunciaba Tomas de Bonilla, cónsul español en Yokohama sobre el asunto:

No puede menos de llamar la atención el súbito envío en las actuales circunstancias de tal agente que sin ser cónsul va a encargarse de un consulado que fue suprimido por su gobierno hace tiempo, que no figura en la guía oficial de Filipinas donde según me aseguran no pasan de quince sus compatriotas.

A mi juicio, el Miura es un agente político de su gobierno que será conveniente vigilar con el mayor cuidado... ${ }^{14}$

Pese a las desconfianzas surgidas y el escaso volumen del comercio entre ambos estados, en el año 1896 se procedió a negociar un nuevo tratado. El objetivo de los nipones era derogar el tratado de 1868 , considerado un tratado desigual, y establecer uno nuevo en mejores condiciones. ${ }^{15}$ Por aquél entonces Japón no disponía de un representante en Madrid, por lo tanto, ese papel de diplomático recaía en el plenipotenciario japonés destinado en París. Pero para negociar el futuro tratado se envió a la capital española al representante japonés en Roma, Kurino Shin'ichiro. ${ }^{16}$ Dicho representante aprovechó su estancia en Madrid para sugerir el establecimiento de una delegación permanente nipona en España y el restablecimiento del consulado japonés en Manila, referido anteriormente. Si bien la representación permanente de Japón en Madrid tardaría años en llegar, el consulado en Manila se reabrió con enorme celeridad; el cónsul japonés se estableció en dicha ciudad el octubre de $1896 .{ }^{17}$

Con la derrota española frente a Estados Unidos en el año 1898 se producía un importante cambio en las relaciones hispano-japonesas. Desde el restablecimiento de las relaciones entre ambos países, la mayoría de los asuntos a tratar estaban estrechamente vinculados a las posesiones hispanas en Extremo Oriente y el Pacífico. Al perder España estas colonias, los principales temas a negociar desaparecen. Aun así, las relaciones diplomáticas entre ambos países no llegaron a romperse.

Con la pérdida de las colonias de ultramar, España dejó de proyectar ambiciones en regiones lejanas, y se centró en las más cercanas, como Marruecos. ${ }^{18} \mathrm{~A}$ su vez, Japón no tenía pretensiones fuera de Extremo Oriente y el Pacífico. Aunque ya no había necesidad de una relación estrecha ni posibilidad de choque de intereses, no se perdió el contacto ni los vínculos diplomáticos. España conservó su representación

\footnotetext{
13 Martínez Taberner, G. (2017): 228.

14 Archivo Histórico Nacional (AHN), Ministerio de Exteriores, expediente Arajiro Miura, año 1896, Caja PP0689, Expediente 09140, s/f. (Yokohama, 22/10/1896).

Pozuelo Mascaraque, B. (1995): 95.

La Gaceta de Madrid, año CCXXXVI, 303, Tomo IV, 30/10/1897, p. 325.

Martínez Taberner, G. (2017): 303.

Rodao, F. (2002): 46.
} 
diplomática en Japón y, a su vez, los nipones establecieron una delegación permanente en Madrid el año 1900, si bien el plenipotenciario japonés no tomó cargo hasta enero de 1901, tal como se anunció en la Gaceta:

Ayer, a las seis y media de la tarde, S. M. la Reina (Q. D. G.), Regente del Reino, acompañada del Excmo. Sr. Ministro de Estado y de los altos funcionarios de la Real Casa, se dignó recibir en audiencia particular al Excmo. Sr. Akabane, quien, previamente anunciado por el Excmo. Sr. Primer Introductor de Embajadores, tuvo la honra de poner en manos de la Augusta Señora las cartas en que S. M. el Emperador del Japón le acredita en calidad de Enviado Extraordinario y Ministro Plenipotenciario en esta Corte. ${ }^{19}$

\section{Representación diplomática y funciones durante el conflicto}

Con la llegada del plenipotenciario japonés a Madrid queda configurada la representación mutua de ambos países que se mantendría hasta después de finalizar el conflicto rusojaponés.

Con respecto a la representación diplomática hispana en Japón, encontramos a Luis de la Barrera, diplomático de carrera, ${ }^{20}$ quien llega a dicho destino el año 1896. Permaneció allí hasta 1907, año en que a petición suya es cesado del cargo. ${ }^{21} \mathrm{Su}$ larga estancia en Japón le permitió dominar la lengua japonesa y establecer una red de contactos fiables.

A lo largo del conflicto rusojaponés, además de sus funciones habituales (representar los intereses de España e informar de los sucesos relevantes en Japón) se sumó la de gestionar todo lo relativo a los agregados militares que el ejército español envió a observar las operaciones militares.

Respecto a la función de informar al gobierno español de todo lo importante, es de destacar el incremento de comunicaciones, tanto telegramas como cartas suyas, que se recibían en el Ministerio de Estado (por entonces el encargado de los asuntos exteriores). Estas alcanzaron un volumen muy superior al habitual. En sus misivas, comentaba los efectos de la guerra en Japón y en sus relaciones con los demás países. Respecto al conflicto en sí, se guardó mucho de efectuar valoraciones personales o dar información fuera de la oficial, así que se limitó, en la mayoría de los casos, a enviar recortes de los reportes oficiales que publicaba el gobierno nipón. Esta actitud puede deberse a la prudencia, pues era consciente del celo de las autoridades niponas a la hora de controlar la información que podían hacer llegar al exterior los extranjeros que estaban en Japón. Él mismo explicó que no daría mucha información del conflicto, excusándose en que todo lo que él podía explicar ya habría llegado al gobierno español por otros medios. ${ }^{22}$ De hecho, tampoco podemos pasar por alto

19 La Gaceta de Madrid, Año CCXL, Núm. 29, Tomo I, 29/01/1901, p. 383.

20 Oscar Javier Sánchez define al diplomático de carrera como "aquellos individuos que ingresaron desde muy jóvenes en el Cuerpo Diplomático, denominados como hombres de la carrera, y lo hicieron desde el último grado del escalafón, el de Agregado sin sueldo, y fueron progresando a lo largo de los años pasando por todas las etapas de la Carrera”. Sánchez Sanz, O. J. (2001): 244.

21 AHN, Ministerio de Exteriores, expediente Luis Barrera, año 1868, Caja PP0129, Expediente 01261, s/f (Tokio, 15/03/1906).

22 AHN, Ministerio de Exteriores, Legajo 2538, Expediente 34, s/f. (Tokio, 16/02/1904). 
algunos casos en que el gobierno nipón expulsó a ciudadanos extranjeros por considerar que enviaban información sensible al extranjero. Así comunicaba el propio Barrera uno de estos casos:

El capitán Bouguïn que como anuncié a V.E. fue procesado por espionaje, ha sido condenado a diez años de trabajos forzados, no por ese delito, pues no resultó probado que comunicara noticias o secretos militares al enemigo, sino por haber transmitido las primeras a oficiales franceses amigos suyos residentes en Francia. Hasta ese punto es severa la legislación japonesa sobre la materia. El Emperador, teniendo en cuenta las circunstancias de este antiguo agregado militar a la legación de la Republica en Tokio y que anteriormente había sido instructor de ese ejército, le ha indultado, pero tendrá que abandonar el Japón donde ha residido tanto tiempo, perdiendo, como es natural, las condecoraciones del país con que se hallaba agraciado. ${ }^{23}$

Tal como expone Barrera, los japoneses fueron estrictos a la hora de perseguir y castigar las filtraciones de información sensible, llegando a la expulsión del señalado oficial francés, pese a los servicios prestados. ${ }^{24}$ Por ello es comprensible que pese al volumen de información que el plenipotenciario hacía llegar a Madrid, este fuese cauto con sus valoraciones personales y no enviar información que pudiera acarrearle problemas.

Respecto a la representación y defensa de España, sus intereses o los de los ciudadanos españoles en Japón, Barrera también tuvo que interceder, como bien era su obligación, en los incidentes y asuntos relacionados con la guerra rusojaponesa que afectaron a los intereses españoles o al papel de este estado con respecto al conflicto. De destacar en este punto es el paso de la Segunda Flota del Pacífico rusa por las aguas de jurisprudencia española, asunto que es tratado más adelante en este trabajo.

Por último, la principal función de carácter extraordinario que Barrera tuvo que llevar a cabo a raíz del conflicto fue la gestión de todo lo relativo al envío de agregados y observadores militares a los ejércitos japoneses. Esto implicó tramitar la petición oficial española ante las autoridades niponas y ayudar a los agregados en su estancia en Japón. ${ }^{25}$ Una vez agregados en los respectivos ejércitos, eran las propias autoridades militares japonesas las que se encargaban de todo lo relativo a los observadores extranjeros. A partir de ese momento, las autoridades niponas hacían llegar a Barrera toda información relativa a los agregados y éste la remitía a Madrid.

En lo que respecta al plenipotenciario japonés en Madrid, Shiro Akabane, apenas vio sus funciones alteradas por el conflicto rusojaponés. Solamente resulta reseñable su papel al representar los intereses de su gobierno ante Madrid a raíz del paso de la Segunda Flota del Pacífico rusa por aguas y puertos españoles.

AHN, Ministerio de Exteriores, Legajo 2539, Expediente. 230, s/f. (Tokio, 25/07/1905).

24 Barrera no lo sabía, pero el capitán al que hace referencia en su comunicación figura entre los agentes que Francia ofreció a Rusia para recabar información en Tokio. Yurievich Sergeev, E (2005): 293.

25 AHN, Ministerio de Exteriores, Legajo 2538, 194, s/f. (Tokio, 20/02/1904) 


\section{España ante el estallido del conflicto rusojaponés}

El ataque japonés a los buques rusos en Port Arthur y Chemulpo fue una sorpresa para el mundo. Hay que matizar que la sorpresa no era el estallido de la guerra, sino que fuesen los japoneses quienes dieran el primer golpe. La guerra se veía bastante probable desde que se empezó a saber que las negociaciones no iban bien. El conflicto bélico se veía tan probable que, en fechas tan temprana como en enero de 1904, algunos militares españoles solicitaron ser destinados como agregados cuando estallase la contienda:

Muy distinguido general y amigo: como según los últimos despachos, aumentan las probabilidades de que de un momento a otro ocurra cualquier incidente armado entre Rusia y el Japón, pongo en conocimiento de V., por si tiene la bondad de hacerlo llegar a noticia del S. Ministro de la guerra, que, en tal caso, me complacería asistir y estudiar oficialmente la campaña... ${ }^{26}$

Así pues, cuando finalmente ocurrió lo que ya pocos dudaban que iba a suceder, el gobierno español fue raudo en declarar su neutralidad frente a la contienda. El posicionamiento de España fue publicado oficialmente en la gaceta oficial el día 11 de febrero:

Rotas, desgraciadamente, las hostilidades entre Rusia y el Japón por el ataque de esta última potencia a la escuadra rusa fondeada en la rada exterior de Port-Arthur, según nota del Sr. Embajador del Imperio ruso en esta Corte, en el día de hoy, el Gobierno de S. M. se cree en el deber de ordenar la más estricta neutralidad a los súbditos españoles, con arreglo a las Leyes vigentes y a los principios del derecho público internacional. ${ }^{27}$

A su vez, las autoridades militares y navales hacían llegar a los almirantazgos y comandancias las instrucciones a seguir para mantener la neutralidad declarada por el gobierno en caso de que algún buque de guerra beligerante llegase a algún puerto español:

Recomiendo así mismo a V.D. que, por tanto, y desde el momento de que tal suceso ocurra, y en tanto no reciba posteriores instrucciones de la superioridad a qué atener su conducta, tenga muy en cuenta los deberes que las Leyes y derecho internacional a los neutrales en estas circunstancias; y en especial la de prevenirle no puede permanecer en puerto más de 24 horas salvo los casos justificados de fuerza mayor; ni permitirles adquirir en plaza más efectos y vituallas que los indispensables... ${ }^{28}$

Con semejantes declaraciones e instrucciones, España se convertía en el primer país en declarar su neutralidad, pues se avanzó a Inglaterra y los demás países. La declaración y observancia de la neutralidad por parte de cada país era especialmente importante, dada la situación internacional. Cada uno de los dos estados beligerantes,

Archivo General del Cuartel General del Ejército (AGCGE), legajo 6210-1, ff 3. (Madrid 12/01/1904).

La Gaceta de Madrid, Año CCXLIII, 42, Tomo 1, 11/02/1904, p. 591.

28 Archivo General de Marina Álvaro de Bazán (AGMAB), legajo 10662, s/f. (Santander, 19/02/1904). 
Rusia y Japón, tenía un convenio defensivo con otra potencia, Francia e Inglaterra respectivamente. Tales convenios obligaban a cada uno de los firmantes a socorrer al otro firmante en caso de entrar en guerra con más de un estado simultáneamente. Esto implicaba que si se daba el caso que otro país decidiese declararse beligerante en el conflicto rusojaponés, tanto Francia como Inglaterra se verían obligadas, por los acuerdos firmados, a entrar en guerra. Esto se veía por entonces como un posible inicio de una confrontación global. Este temor a un conflicto mundial se mantuvo a lo largo de la contienda, pues pese al posicionamiento inicial de cada país, esto podía cambiar si sucedía algún incidente importante.

A lo expuesto en el párrafo anterior, hay que añadir que la neutralidad española perseguía intereses propios. Con la neutralidad frente al conflicto rusojaponés, y aprovechando las rivalidades entre franceses e ingleses, pretendía lograr una mejor posición a la hora de defender sus intereses en Marruecos. ${ }^{29}$

\section{La Segunda Flota del Pacífico en Vigo y la reacción nipona}

Una vez declarada la neutralidad y comunicadas las instrucciones pertinentes para observar de la manera más estrictamente posible dicha posición, no sucede ningún incidente importante entre España y Japón hasta que Rusia envía una flota de refuerzo desde el Báltico. Dicha flota, bautizada como Segunda Flota del Pacífico, se vio en necesidad de recalar en Vigo. Esto molestó al gobierno nipón, que se apresuró a comunicar su indignación al gobierno español. Esta sería la principal alteración de las relaciones hispano-japonesas a raíz de la guerra rusojaponesa.

Lo que en principio iba a ser una victoria relativamente fácil para las armas rusas se fue tornando en una humillante sucesión de derrotas tanto en tierra como en mar. Japón supo sacar ventaja tanto de su ataque naval inicial como de todos los elementos disponibles para enfrentarse a Rusia. En tierra, dada su inferioridad inicial, las fuerzas del zar no podían hacer otra cosa que reunir efectivos hasta verse capaz de tomar la iniciativa. Este era un proceso lento dado que tanto la tropa como el avituallamiento debía llegar desde Europa con el Transiberiano, que por entonces consistía en una línea ferroviaria de una sola vía.

En mar, el goteo de pérdidas experimentadas por la flota rusa del Pacífico la volvieron completamente inoperativa. Eso otorgó el control del mar a Japón, lo cual era vital para los nipones, pues el mantenimiento del ejército en el continente pasaba por garantizar las líneas de suministros y refuerzos desde el archipiélago. Por ello, y por la obsesión de San Petersburgo de no dejar caer la fortaleza naval de Port Arthur, se resolvió enviar al teatro de operaciones a todos los buques disponibles en el Báltico. Los objetivos eran socorrer dicha fortaleza y los buques allí refugiados y arrebatar el control del mar a la flota nipona.

La bautizada como Segunda Flota del Pacífico tenía por delante una misión sin precedentes en la historia. Jamás antes una flota beligerante había tenido que llevar a cabo un viaje de tales dimensiones, teniendo como punto de partida Libau, en el Báltico, y como destino Port Arthur o Vladivostok. Entre medio, debía rodear África, cruzar el Índico, el sudeste asiático y la costa china. Todo ello con la complicación

29 Calderón de la Barca, V. (1995): 160-161. 
de no disponer de bases propias por el camino y viendo muy difícil poder recalar en puerto alguno, dado que todos los países se habían declarado neutrales y por lo tanto no podían socorrer, salvo en casos excepcionales, a una flota destinada al combate.

El viaje de la flota estuvo marcado por múltiples infortunios. Partió de su base en el Báltico el día 2 de octubre de 1904. Cuando cruzaba el mar del Norte, en plena noche, confundió una flota pesquera inglesa por buques japoneses. Varios buques rusos abrieron fuego contra los pescadores. ${ }^{30}$ Esto supuso un grave incidente y el gobierno inglés solicitó a Rusia que detuviera el avance de sus buques hasta haber llegado a un acuerdo con respecto al incidente.

Así fue como una porción importante de la flota rusa, 4 de sus acorazados, se vio obligada a detenerse en la bahía de Vigo a finales del mes de octubre de 1904. Su entrada a dicha bahía se notificó el día 26 de octubre:

A las $10 \frac{1}{2}$ llegaron cuatro acorazados rusos, Alejandro III, Borodino, Orel, Knyaz Suvorov y el transporte Anadyn. Enseguida fui a bordo almirante invitándole saliera a la mar. Dijo destacó escuadra los cuatro barcos por traer averías máquina. Cree tardarán cuatro días en remediarlas y solicita del Gobierno S.M. autorización para carbonear. ${ }^{31}$

La reacción de las autoridades niponas no se hizo esperar. Dada la preocupación ante la posibilidad de perder el control absoluto del mar, decidieron comunicar su descontento al gobierno español por lo que ellos consideraban una violación de la neutralidad. El 29 de octubre llegaba al Ministerio de Estado un comunicado desde la legación japonesa en que exponían los motivos por los que creían que, debido a la neutralidad declarada por España, los buques rusos no podían detenerse en ningún puerto de jurisprudencia española sin violar las normas de neutralidad. En dicho comunicado, el gobierno nipón se expresaba de manera contundente:

...el gobierno Imperial está convencido de que, si la escuadra rusa obtiene el permiso de permanecer en las aguas neutrales donde no exista ningún peligro de los ataques del enemigo y de tomar carbón libremente y sin restricción y continuar así su viaje expedicionario al extremo oriente, dichas aguas neutrales serán convertidas virtualmente en punto de apoyo y base de operación para la escuadra rusa en clara violación de la neutralidad. ${ }^{32}$

Los términos con los que el gobierno japonés se expresaba venían a indicar que todo puerto en que la escuadra rusa recalase sería considerado base de operaciones rusa y por lo tanto base enemiga del Imperio Japonés. De seguir estrictamente sus propias palabras, y dado que hacía 3 días que 4 acorazados rusos se hallaban en Vigo, Japón podría haber considerado dicho puerto como base enemiga y, por consiguiente, que España había entrado en el conflicto del lado de Rusia.

Si bien la flota rusa abandonó las aguas españolas poco después, su parada en Vigo provocó que durante los meses siguientes se produjeran varios contactos diplomáticos entre España y Japón para dirimir el asunto.

Connaughton, R. (2004): 301.

AGMAB, legajo 10662, s/f. (Vigo, 26/10/1904).

AHN, Ministerio de Exteriores, legajo 2539, expediente 191, s/f. (Madrid, 29/10/1904). 
El día 6 de noviembre, el plenipotenciario español en Tokio comunicaba al ministerio de Estado las noticias que sobre este tema habían sido publicadas en Japón. También comentaba que, aun sin haber recibido instrucciones, tomó la iniciativa de ir a tratar el asunto con el Ministerio de Negocios Extranjeros nipón:

...creí oportuno ir a ver de un modo confidencial al viceministro a fin de preguntar si era cierto cuanto la prensa informaba acerca del asunto.

Nada concreto pude obtener del Señor Chinda, que se encerró en vaguedades y respuestas contradictorias. Por mi parte le hice presente que mi visita no revestía carácter oficial alguno por carecer de instrucciones e informes oficiales y que solo tenía por objeto hacer constar que el suministro de carbón a la flota del Báltico en Vigo suponiendo que fuese cierto, no constituía en modo alguno el quebrantamiento de la neutralidad de España sino simplemente aplicación por esta del principio de Derecho Internacional generalmente reconocido y adoptado por este Imperio al decretar las reglas de su neutralidad cuando la guerra hispano-americana... ${ }^{33}$

Respecto lo que comenta sobre la información de la prensa, se refiere a que esta había comunicado que el gobierno nipón había presentado formalmente una queja, cosa incierta pues aún no se había presentado, pero se estaba preparando. Pese a no haber recibido instrucciones, Barrera hizo un enorme favor a su gobierno al tomar la iniciativa y caer en la cuenta de que la actuación española con respecto a la flota rusa entraba en los márgenes de las reglas de neutralidad que el propio Japón adoptó ante la guerra hispanoamericana.

A principios del siglo XX no existía un protocolo internacional que estableciese las reglas exactas que debía seguir cada estado en caso de declararse neutral ante un conflicto bélico. Así que, en el momento en que transcurre el conflicto rusojaponés, cada país dictaminaba sus propias reglas de neutralidad. De ello se lamentaba el ministro de relaciones exteriores británico, Lord Lansdowne, en una conversación con el representante español en Londres a principios de 1905:

No solo convino fácilmente mi ilustre interlocutor en que es de desear que los neutrales tengan unas mismas reglas y se inspiren en un mismo espíritu, (...) es difícil dar unidad a la conducta de los neutrales, porque como los intereses son muy complejos y diversos, necesariamente lo son también las reglas dictadas para cada país. Así, por ejemplo, resulta que Inglaterra tiene la regla de la estancia de solo 24 horas para buques de guerra beligerantes y Francia no la tiene, por lo cual en Argel hubo un caso que pudo complicarse. Sabe, sin embargo, que, en cuanto a aguas territoriales, Francia aplica a la escuadra hacia Madagascar la misma prohibición de servirse de ellas que Inglaterra cerca de Reino Unido. ${ }^{34}$

En el caso de España ante la guerra rusojaponesa, tal como señaló Barrera, siguió una regulación similar a la que Japón usó en su neutralidad ante la guerra hispanoamericana. Este se volvería el principal argumento que las autoridades españolas esgrimirían para defenderse ante las acusaciones niponas de haber violado la neutralidad.

33 Ibid, s/f. (Tokio, 06/11/1904).

34 AHN, Ministerio de Exteriores, legajo 2539, expediente 191, s/f. (Londres, 12/01/1905). 
La discusión entre ambos gobiernos continuó a lo largo de noviembre y diciembre. Pese a la respuesta dada por el plenipotenciario español en el ministerio de Negocios extranjeros, el representante nipón en Madrid siguió esgrimiendo sus argumentos en su siguiente comunicado del día 19 de noviembre:

Los barcos que componen la escuadra del Báltico constituyen una expedición naval, teniendo el propósito y destino abiertamente hostiles. El permitir en estas circunstancias a los barcos de esa escuadra el aprovisionamiento de carbón en Vigo para que puedan proseguir su empresa belígera era, al parecer del Gobierno Imperial, convertir dicho puerto en una base de operaciones belicosas contra el Japón y dar a los barcos rusos importante ayuda y asistencia en apoyo a sus proyectos hostiles. Creyendo ser inconsistente tal acto con los deberes de la neutralidad de España y perjudicial a los derechos beligerantes del Japón, el gobierno Imperial cree obligado a protestar... ${ }^{35}$

En este fragmento se puede ver que, pese al argumento presentado por Barrera en Tokio, el gobierno nipón y su representante en Madrid mantenían el tono y las graves acusaciones. Esta vez sí, declaraban que, con su actuación, España había convertido Vigo en una base de operaciones belicosas contra Japón. Anunciaba, además, que se iba a presentar una protesta formal.

A estas reclamaciones el gobierno español respondió que no veía violación alguna de la neutralidad en su actuación, llegando a indicar que la protesta que Japón presentaba no procedía. Así se hizo saber al plenipotenciario japonés en Madrid:

A pesar de los términos corteses y de la forma amistosa con que VE cumple el encargo de su gobierno, no puedo menos de manifestarle que a mi juicio no procede dicha protesta, pues nadie mejor que VE ha podido apreciar, bien de cerca, la escrupulosa corrección con que España entera y especialmente su gobierno, observan la más estricta y severa neutralidad... ${ }^{36}$

Pese a las respuestas dadas por el gobierno español, la insistencia del representante nipón en Madrid a lo largo del mes de diciembre obligó al ministerio de Estado a solicitar a Barrera que intentase hacer cambiar de parecer a las autoridades japonesas. Este obró con diligencia y el día 26 de diciembre, solo dos días después del requerimiento de sus superiores, respondía con el siguiente telegrama:

Ministro negocios extranjeros accede siguiente explicación. Persuadido que España no ha obrado por espíritu alguno parcialidad, insiste, sin embargo, por considerarlo de vital interés para Japón en estos momentos, en mantener con firmeza que el principio derecho internacional no es aplicable caso especial presente. ${ }^{37}$

Barrera logró reducir el tono en que el gobierno nipón llevaba el asunto, de manera que este no viera en la actuación española ningún mal deseo contra Japón, si bien aún veía la actuación española como una violación de las leyes de neutralidad.

\footnotetext{
AHN, Ministerio de Exteriores, legajo 2539, expediente 191, s/f (Madrid, 19/11/1904).

Ibid, s/f. (Madrid, 24/11/1904).

Ibid, s/f. (Tokio, 26/12/1904).
} 
El 27 de diciembre, el día siguiente al envío del telegrama, el plenipotenciario español escribió una detallada carta narrando su encuentro con el ministro japonés de negocios extranjeros. Describe la reunión como muy amistosa, igual que la actitud de dicho ministro. De hecho, en dicha comunicación comenta que logró convencer al político japonés para que no fuese presentada definitivamente la protesta formal:

...el señor ministro me manifestó que accedía desde luego a la justa demanda de VE y que acto continuo telegrafiaría al señor Akabane para que, si no había presentado aún la protesta, suspendiera el hacerlo y discutiese de nuevo el caso con VE. ${ }^{38}$

Dos días después, el propio ministerio de estado comunicaba a Barrera el éxito de su gestión:

Gestión VE surtió efecto. Akabane suspende protesta esperando instrucciones... ${ }^{39}$

Pese al logro de Barrera al convencer a las autoridades japonesas para que no presentasen formalmente su queja, durante los meses de enero y febrero el asunto seguiría dirimiéndose. De todas formas, el tono empleado ya no sería tan grave, por lo que ya no encontramos en los comunicados nipones la consideración de Vigo como base naval enemiga.

Ante la insistencia japonesa en no reconocer que España había obrado bien en el asunto, el gobierno español decidió consultar el parecer de las principales potencias sobre su actuación. Curiosamente sería Inglaterra, el principal apoyo internacional de Japón, quien se expresaría más a favor de España en este asunto. Así lo comunicaba el embajador español en Londres después de reunirse con el ministro de asuntos exteriores británico:

Contestome Lord Lansdowne que algo sobre este mismo asunto le había hablado no hace mucho tiempo el Duque de Mandos, añadiendo que no se le alcanzaba motivo alguno de formular quejas contra España, toda vez que esta se había atendido a las leyes de neutralidad establecidas internacionalmente y reconocidas por el Japón. (...) y que además el precedente sentado por España en la ocasión aludida debía servirnos de norma caso de ocurrir de nuevo contingencia semejante con uno u otro de los estados beligerantes en el curso de las presentes hostilidades. ${ }^{40}$

Cabe señalar que Inglaterra tenía motivos para apoyar la actuación de España. El puerto de Vigo fue el primer lugar donde la flota rusa pudo detenerse después de haber hundido por accidente algunos buques pesqueros ingleses. Permitir que el almirante ruso permaneciese en dicho puerto facilitó que el incidente no fuese a más. Así, para cuando los acorazados rusos abandonaron la bahía de Vigo, ya se había llegado a un acuerdo entre Rusia e Inglaterra para formar una comisión que investigase el incidente. ${ }^{41}$

Poco más insistió Tokio en el asunto. El visto bueno expresado por Inglaterra a la manera de actuar de España dejaba a Japón sin ningún apoyo en su protesta.

\footnotetext{
Ibid, s/f. (Tokio, 27/12/1904).

Ibid, s/f. (Madrid, 29/12/1904).

Ibid, s/f. (Londres, 01/03/1904).

41 Warner, D / Warner, P. (1974): 417.
} 
Este incidente diplomático fue la principal alteración que experimentó la relación entre ambos países en el marco de la guerra rusojaponesa. En la documentación consultada no se aprecia ningún otro asunto que afectase lo más mínimo a los vínculos entre Japón y España. A lo sumo, se podría reseñar una reflexión que el propio representante español en Tokio hizo llegar a Madrid el día 27 de abril de 1905:

...y si dicha escuadra [rusa] obtuviera el triunfo sería grandísimo el rencor contra todos los países que en mayor o en menor escala la han auxiliado... ${ }^{42}$

Justo un mes después de esta comunicación, el 27 de mayo, tenía lugar la batalla de Tsushima, en la que la flota rusa resultó aniquilada por la armada japonesa. De esta manera la observación de Barrera no se vio cumplida y, por lo tanto, Japón no tenía motivos para tener sentimientos hostiles hacia España por su actuación.

\section{España ante el fin de la guerra rusojaponesa.}

Como se ha explicado más arriba, el principal acontecimiento que pudo provocar un importante cambio en las relaciones hispano-japonesas durante el conflicto rusojaponés fue la acogida brindada, de manera más o menos voluntaria, a la flota rusa que se dirigía al teatro de guerra. Al margen de este suceso, a lo largo de dicha contienda las relaciones siguieron siendo distantes, pero no malas.

Al igual que en el resto del mundo, el fin del conflicto fue recibido con un gran alivio en España. Se lograba ahuyentar el fantasma de un conflicto global. La victoria japonesa fue acogida con una mezcla de distintos sentimientos y sensaciones, desde admiración a recelo, a lo largo y ancho del mundo.

Al margen de cómo fuese percibida la victoria nipona en cada país, lo cierto es que se produjo un cambio generalizado hacia la nueva potencia mundial. Los principales poderes de Europa, incluida Rusia, y Estados Unidos elevaron sus delegaciones en Tokio al grado de embajadas:

En vista del curso extraordinariamente triunfante de la guerra, se creyó seguro que terminada esta las grandes potencias se apresurarían a elevar el rango de sus respectivas misiones en Tokio. Inglaterra ha dado el ejemplo nombrando Embajador a su ministro aquí Sir Claude Mac-Donald y se considera como muy probable que harán en breve lo propio Alemania, América, Francia y Rusia. ${ }^{43}$

Inglaterra y la República de la Unión (Estados Unidos) han notificado ya oficialmente a este gobierno que sus representaciones en Tokio han sido elevadas al rango de Embajadas y el Ministro de Gran Bretaña Sir Claude Mac-Donald ha obtenido ya el reconcomiendo de su rango de Embajador. Francia y Alemania anuncian las Agencias que han acordado igualmente crear Embajadas en el Japón y hasta indican que el Embajador de la Republica en Berna ha sido nombrado para igual cargo aquí. Falta solo Rusia entre los cinco grandes estados a quienes enviará el Japón embajadores por corresponder a esta iniciativa, pero no se duda aquí que seguirá el ejemplo de los otros cuatro. ${ }^{44}$

\footnotetext{
AHN, Ministerio de Exteriores, legajo 2539, expediente 182, s/f. (Tokio, 27/04/1905).

AHN, Ministerio de Exteriores, legajo 1634, s/f. (Tokio, 06/11/1905).

Ibid, s/f. (Tokio, 30/11/1905).
} 
La elevación a rango de embajadas de las distintas legaciones en Tokio implicaba no sólo un acercamiento de las potencias a Japón, sino el reconocimiento internacional de su ascenso a potencia de primer orden. La victoria en el campo de batalla frente a Rusia fue el hecho que elevó Japón a uno de los países más poderosos del momento, y el ascenso a embajadas de las legaciones extranjeras se puede interpretar como el reconocimiento simbólico por parte de las principales potencias.

España no las imitó. Esto se puede explicar por la indiferencia que mostraba España con respecto a los países de Extremo Oriente. Tal indiferencia llegó al punto de plantearse una reducción del número de legaciones en la región, si bien finalmente no se llevó a cabo esta idea. ${ }^{45}$ Tampoco surgió por parte de los representantes españoles en Tokio propuesta alguna de elevar la legación a embajada.

A parte del nombramiento de embajadas, se produjeron otras acciones que podrían considerarse derivadas de la victoria nipona e implicaban un estrechamiento de relaciones entre distintos países con Japón. La más significativa fue la renovación de la alianza anglo-japonesa de 1902 que incluía nuevas cláusulas. ${ }^{46}$ Incluso países de escaso peso internacional se apresuraron a estrechar lazos con Japón. Un ejemplo sería Portugal, que estableció una línea de vapores directa entre Lisboa y el archipiélago nipón. Así lo comunicaba el cónsul español en Yokohama:

...según noticias recibidas recientemente de Portugal, la Hamburg-America Ss Compañía ha convenido un arreglo con el gobierno portugués para establecer un servicio directo mensual entre Lisboa y el Oriente, haciendo escala en Hong Kong, al vecino puerto portugués de Macao y puertos de China y del Japón. ${ }^{47}$

En el caso de España, no se produjo ninguna variación ni reacción que expresasen una intención de mejorar o estrechar las relaciones con la nueva potencia. Esto no fue bien visto por los representantes españoles en Japón. Por ello, tanto desde el consultado en Yokohama como desde la legación en Tokio, se produjeron varias peticiones para que España se sumase a la corriente internacional de acercamiento a Japón. En la misma comunicación en que anunciaba el establecimiento de la línea de vapores entre Lisboa y Japón, el cónsul en Yokohama instaba al gobierno de Madrid a intentar sacar provecho de esa nueva línea:

¿No sería fácil y provechoso obtener de la Hamburgo-América compañía que se consintiese en establecer una escala en puerto español, Cádiz o Barcelona por ejemplo?

Puede decirse que actualmente el comercio entre España y el Japón es casi nulo y en gran parte se debe este lamentable estado de cosas a la carencia absoluta de medios de comunicación directos ¿Debe seguir nuestro país apartado en absoluto de estos mercados del Extremo Oriente en un momento en que después del esfuerzo asombrosos efectuado por el Japón en estos últimos años, se ve a todas la naciones importantes de Europa y América tratar de aumentar y estrechar en lo posible sus relaciones políticas y comerciales con este Imperio ${ }^{48}$

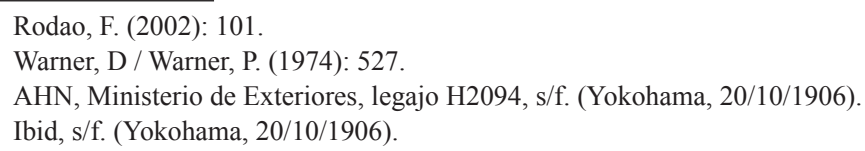


Por otro lado, el plenipotenciario español en Tokio expresó la necesidad de disponer de un agregado militar en su legación:

...sería de una utilidad suma la presencia en esta Legación de un agregado militar siendo muy de lamentar que no haya podido quedar aquí el Señor coronel de que se trata y sobre todo si no ha de ser reemplazado. ${ }^{49}$

En el caso de esta petición, aún con un cierto retraso, fue debidamente atendida. A principios del año 1908 se determinó enviar como agregado militar a Eduardo Herrera, quien había seguido el conflicto rusojaponés como observador en el ejército nipón:

Dada la extraordinaria importancia que ha adquirido el Imperio del Japón, muy principalmente en las partes militares, y como consecuencia de esto, la utilidad de estudiar cuanto se relaciona con dicho país y especialmente con su ejército, el rey ha tenido a bien disponer se signifique a VE la conveniencia de enviar un agregado militar a la legación de España en aquel Imperio y que para desempeñar este cargo sea nombrado el Comandante de Estado Mayor del Ejército Don Eduardo Herrera de la Rosa, que tiene condiciones muy recomendables para el desempeño de sus cometidos. ${ }^{50}$

Posiblemente detrás de este nombramiento no había solamente interés en el estudio del ejército japonés. El nombramiento de Herrera pudo estar condicionado por la buena imagen que se tenía de él por parte de los nipones. Así pues, esta decisión podría tener también el objetivo de mejorar la imagen de España en Japón, en un momento en que los militares empezaban a ganar un importante peso en la política en dicho país. Así se expresaba el plenipotenciario español en Pekín, quien hasta hacía poco había servido de secretario en Tokio, respecto al aprecio que le tenían a Herrera en Japón:

Un agregado militar de España en Japón era indispensable. Y no se pudo hacer nombramiento más acertado. El señor Herrera de la Rosa, fue, de todos, absolutamente de todos los agregados militares, españoles y extranjeros, en la campaña con Rusia, el que más se distinguió: El que más, y mejor que nadie, supo pactarse las simpatías, consideraciones y respeto de Generales, jefes, oficiales y soldados japoneses. Lo sé por qué los japoneses me lo han dicho. Así también, no se guarda hoy en el Japón, dentro de las conveniencias que a todos se deben, por parte de los militares japoneses, a ningún otro agregado, la consideración de afectuoso aprecio que tiene por el señor Herrera de la Rosa. ${ }^{51}$

A Herrera también se le encomendó el estudio de las fuerzas militares de China y Siam, si bien solamente podía destinar dos meses al año a viajar y observar estos

\footnotetext{
49 AHN, Ministerio de Exteriores, Expediente José Sanchis, año 1902, caja PP 1113, EXP. 15206, s/f. (Tokio, 28/04/1906).

50 AHN, Ministerio de Exteriores, Expediente Eduardo Herrera, año 1929, caja PP 1244, EXP. 19865, s/f. (Madrid, 17/03/1908).

51 Ibid, s/f. (Pekín, 08/05/1909).
} 
países. Esto muestra que dentro de la poca atención que prestaba España a Extremo Oriente, Japón era el país que mayor interés despertaba de la región. Esto se debe, indudablemente, a la sorprendente victoria militar nipona frente a Rusia.

\section{Conclusiones}

Como se ha señalado anteriormente, la guerra rusojaponesa y victoria nipona frente a los rusos supuso el principal acontecimiento global del siglo XX hasta el estallido de la Primera Guerra Mundial. Las relaciones de Japón con varios países fueron mutando desde los inicios del conflicto. Su victoria provocó que estos cambios diplomáticos y comerciales fuesen aún mayores. Se puede apreciar una enorme diferencia entre los vínculos que tenía Japón con el exterior en 1903 con los que tenía al finalizar el año 1906.

En el caso concreto que se atiende en el presente artículo, podemos observar que las relaciones de España con Japón apenas experimentaron cambios importantes durante e inmediatamente después de la contienda rusojaponesa. Solamente resulta reseñable, dentro del periodo de duración de la guerra, la amenaza nipona de presentar una queja formal por la acogida dada a la flota rusa en Vigo a finales de octubre de 1904. Pese a las duras palabras empleadas por Japón ante lo que consideraba un quebrantamiento de la neutralidad por parte de España, el buen hacer del plenipotenciario español en Tokio logró que el tono fuese rebajándose. Finalmente, y pese a la insistencia nipona en que las autoridades españolas actuaron mal, el asunto fue perdiendo importancia ante la poca solidez de los argumentos nipones y el poco apoyo internacional a su queja. Así, en pocos meses, todo volvió al estado anterior al suceso.

Fuera de este asunto, las relaciones y vínculos hispano-japoneses no experimentaron variación alguna durante el conflicto.

Por lo que respecta a la reacción española por la victoria japonesa, fue también muy leve y tardía, comparada con las de otros países. Como se ha expuesto, para 1906 las potencias habían elevado a embajadas sus respectivas representaciones diplomáticas en Tokio y hasta Portugal había establecido una ruta comercial directa entre su capital y Japón. España no hizo ningún movimiento hasta el año 1908, nombrando un agregado militar para la legación de Tokio, y esto se debió sobre todo a la insistencia de los representantes españoles en la región y al interés que las fuerzas armadas niponas habían despertado en el ejército español.

Por su parte, las autoridades japonesas tampoco mostraron interés en mejorar de alguna manera los vínculos con España ni durante ni después del conflicto con Rusia. Una vez firmada la paz, fueron las distintas potencias y países los que tomaron la iniciativa para mejorar los vínculos con Japón. A ello hay que sumar que las autoridades niponas tenían que gestionar los resultados de la guerra y la victoria. Por todo esto no es de extrañar que no surgieran iniciativas niponas de acercamiento a España inmediatamente después del conflicto con Rusia.

Las relaciones hispano-japonesas seguirían siendo amistosas, pero con escasa relevancia y sin jugar, por ninguno de los dos bandos, un papel relevante en los intereses del otro. De hecho, tal como se ha señalado previamente, no se planteó siguiera elevar la delegación española en Tokio a embajada, como si hicieron varios países. 
Esta situación duró hasta que las respectivas representaciones de uno y del otro no fueron elevadas a embajadas hasta pasados muchos años, en $1952 .{ }^{52}$

En conclusión, tanto el conflicto rusojaponés como su resolución no afectaron a las relaciones hispano-japonesas de manera significativa. La única variación reseñable y duradera fue el nombramiento de un agregado militar para la legación en Tokio. Salvo esto, el vínculo se mantuvo igual que antes de la guerra rusojaponesa. Quedaba España rezagada de la tendencia mundial de aproximación, con más o menos recelo en algunos casos, a la nueva potencia en búsqueda de una provechosa mejor relación con ella.

\section{Archivos}

Archivo General del Cuartel General del Ejército (AGCGE).

Archivo General de Marina Álvaro de Bazán (AGMAB).

Archivo Histórico Nacional (AHN)

\section{Bibliografía}

Calderón de la Barca, Víctor (1995): "Las salpicaduras de una guerra lejana. La guerra ruso-japonesa de 1904-1905 y la neutralidad española según la Prensa española de la época”. En Revista Española del Pacifico, 5, pp. 151-170.

Connaughton, Richard (2004): Rising sun and tumbling bear, Russia's war with Japan. Londres: Cassell.

Kowner, Rotem (Ed.) (2007): The impact of the ruso-japanese war. Londres y New York: Routledge.

La Gaceta de Madrid, Año CCXL, Núm. 29, Tomo I, 29/01/1901.

La Gaceta de Madrid, Año CCXLIII, Núm. 42, Tomo 1, 11/02/1904.

Martínez Taberner, Guillermo (2017): El Japón Meiji y las colonias asiáticas del imperio español. Barcelona: Edicions Bellaterra.

Nish, Ian (1977): Japanese Foreign policy, 1869-1942: Kasumigaseki to Miyakezaka. Londres: Routledge \& Kegan Paul Books.

Nish, Ian (1987): The Origins of the Russo-Japanese war. Londres y New York: Longman Group.

Pérez Martínez, Arturo (2018): Aspectos de Japón vistos por un diplomático español. Gijón: Satori Ediciones.

Pozuelo Mascaraque, Belén (1995): "Las relaciones hispano-japonesas en la era del Nuevo Imperialismo (1885-1895)”. En: Revista del Pacifico, 5, pp. 79-106.

Sánchez Sanz, Oscar Javier (2001): "La formación del diplomático 1890-1914: ¿elitismo o profesionalismo?". En Cuadernos de historia contemporánea, 23, pp. 241-270.

Reyes Manzano, Ainhoa (2009): "La guerra ruso-japonesa a través del Diario de la Rioja". En Teka Komisji Historycznej OL PAN, 6, pp. 85-113.

Rodao, Florentino (2002): Franco y el Imperio japonés. Barcelona: Plaza \& Janés.

Togores Sanchez, Luis Eugenio (1995): "El inicio de las relaciones hispano-japonesas en

52 Pérez Martínez, A. (2018): 39. 
la época contemporánea (1868-1885)". En: Revista española del Pacifico, 5, pp. 17-42. Warner, Denis / Warner, Peggy (1974): The tide at sunrise. A history of the Russo-Japanese war 1904-1905. Norwich: Charterhouse Books.

Yurievich Sergeev, Evgenii (2005): "Russian military intelligence in the war with Japan, 1904-1905”. En: Steinberg, John W./ Menning, Bruce W./ Schimmelpenninck Van Der Oye, David/ Wolff, David/ Yokote, Shinji (eds.): The Russo-Japanese war in global perspective: World war zero Vol I. Leiden-Boston: Brill, pp. 281-304. 